\title{
Safety and efficacy of large balloon sphincteroplasty in a third care hospital
}

\author{
Eduardo Martín-Arranz, Rafael Rey-Sanz, María Dolores Martín-Arranz, Francisco Gea-Rodríguez, \\ Pedro Mora-Sanz and José María Segura-Cabral
}

Department of Digestive Diseases. Hospital Universitario La Paz. Madrid, Spain

\begin{abstract}
Background and aims: large balloon sphincteroplasty (LBS) associated with sphincterotomy (ES) has gained acceptance as a useful tool in extracting difficult bile duct stones. Our purpose was to evaluate the efficacy and safety of LBS with balloons $\geq 10 \mathrm{~mm}$ in clinical practice setting.

Patients and methods: unicentre prospective study in a tertiary care hospital. All patients who underwent LBS associated with ES between July 2007 and March 2011 were included prospectively in a database recording clinical aspects, procedure data, outcome and complications.

Success is the main outcome defined as complete stone removal documented by absence of any filling defect during a final occlusion cholangiogram and absence of clinical or radiological findings after the ERCP consistent with remaining stones. Complications as pancreatitis, cholangitis, post-ERCP bleeding, perforation and others were also measured.

Results: one hundred twenty procedures were made in 109 patients with balloons ranging from 10 to $20 \mathrm{~mm}$. Success rate was $91 \%$ in the first attempt and $96.7 \%$ after two procedures. Mechanical lithotripsy was only needed in one case $(0.8 \%)$. Complication rate was $4.2 \%$ due to five cases of post-ERCP bleeding in high risk patients.

Conclusion: large balloon sphincteroplasty associated to sphincterotomy in clinical practice is a very effective and safe technique.
\end{abstract}

Key words: Endoscopic retrograde colangiopancreatography (ERCP). Sphincterotomy. Balloon dilation. Choledocholitiasis.

Martín-Arranz E, Rey-Sanz R, Martín-Arranz MD, Gea-Rodríguez F, Mora-Sanz P, Segura-Cabral JM. Safety and efficacy of large balloon sphincteroplasty in a third care hospital. Rev Esp Enferm Dig 2012;104:355-359.

Received: 11-01-2012.

Accepted: 23-05-2012.

Correspondence: Eduardo Martín Arranz. Servicio de Aparato Digestivo. Hospital Universitario La Paz. Paseo de la Castellana, 261. 28046 Madrid, Spain

e-mail: emartina.hulp@salud.madrid.org

\section{INTRODUCTION}

Endoscopic retrograde cholangiopancreatography (ERCP) and sphincterotomy (ES) were developed in the 1970 's $(1,2)$, and have led to a huge progress in diagnosis and treatment of biliar and pancreatic diseases, being especially significant in the management of choledocolithiasis.

Despite its extraordinary efficacy, over 80-90\% (3), stone removal can still be challenging due to stone size or anatomical factors such as duodenal diverticulum, previous surgeries, strictures, coagulation disorders, etc. (4).

In order to overcome these situations there are different therapeutic options such as mechanical, hydraulic or laser lithotripsy (3). In the last years, large-balloon sphincteroplasty (LBS) has raised great interest (5-12).

\section{OBJECTIVE}

To prospectively evaluate the efficacy and safety of sphincteroplasty with large diameter balloons associated to endoscopic sphincterotomy for difficult bile duct stone removal in clinical practice setting.

\section{MATERIAL AND METHODS}

All patients undergoing LBS during an ERCP since July 2007 were included in a database. LBS was defined when the balloon used was larger than $10 \mathrm{~mm}$ in diameter.

Baseline patient characteristics, endoscopic findings, procedure data and post-procedure complications were recorded. Balloon dilation due to other causes than choledocolithiasis such as post-surgical stenosis were excluded (Table I).

Around 270 procedures are performed annually in our centre by five endoscopists, four of then with over 10 years of ERCP experience. 
Table I. Demographic variables

\begin{tabular}{ll}
\hline Sex & Male 55 (40.4\%) \\
\hline Age & Median 75.9 Range 25-97 \\
\hline Dilation cause & Discrepancy between stone size \\
& $\begin{array}{l}\text { and distal bile duct diameter 62\% } \\
\text { Duodenal diverticula 20.8\% } \\
\text { Non extendable prior ES 10\% } \\
\text { Severe coagulopathy 6.7\% } \\
\text { Billroth II gastrectomy II 0.8\% }\end{array}$ \\
\hline Prior cholecistectomy & 37 (30.8\%) \\
\hline
\end{tabular}

Procedures took place under anesthesiologist controlled sedation as is usual in our centre. Side-viewing endoscopes used were TFJ145 or TFJ160 (Olympus Optical Co Ltd, Tokyo, Japan). For ES an electric generator was used (Erbe Elektormedizin $\mathrm{GmbH}$, Tubingen, Germany).

Informed consent was obtained prior to the procedure in all cases.

ERCP indication, cannulation and cholangiogram were performed according to clinical, endoscopic and radiological findings, trying to remove the stones by using Fogarty balloons. When previous ES was present it was extended if judged possible.

If stone extraction was not possible with standard maneuvers (ES, Fogarty balloon, conventional baskets) and the ES could not be extended a LBS was performed, with wireguided hydrostatic CRE balloons between 10 and $20 \mathrm{~mm}$ (Boston Scientific Corp Ltd, Cork, Ireland). These balloons are multiradial, which allow different inflation diameters according to the pressure reached. This pressure is controlled with a manometer, following manufacturer instructions.

Balloon inflation with diluted contrast to enhance visualization was done under endoscopic and fluoroscopic guidance, placing the medial portion across the papilla, observing the waistline disappearance and maintaining the balloon inflated at least one minute.

Diameter of the balloon was decided by the endoscopist, based on stone size and bile duct diameter, beginning with the smallest that was considered as effective and progressively increasing if the result was not satisfactory, however it could never exceed the maximum diameter of the bile duct in order to avoid complications. Balloon size registered for this study was the largest used diameter.

After LBS was performed, stones were removed with Fogarty catheters. Dormia basket or mechanical lithotripsy were used if deemed necessary.

Procedure success was defined as complete stone removal documented by absence of any filling defect during a final occlusion cholangiogram and absence of clinical or radiological findings after the ERCP consistent with remaining stones.

\section{Assessment of complications}

Patients were observed for at least 24 hours. Clinical and blood testing were obtained before discharged home. Readmissions due to complications after discharge were also recorded.

Complications were defined and graded following consensus (13). Post-ERCP pancreatitis was defined as persistent abdominal pain associated with an elevation of amylase serum level greater than 3 times the upper normal limit. Hemorrhage was defined as the presence of clinical evidence as melena or hematemesis, decrease of hemoglobin levels in at least $2 \mathrm{~g} / \mathrm{dl}$, transfusion need or direct endoscopic visualization. Post-ERCP cholangitis was defined as fever $\left(>38^{\circ} \mathrm{C}\right)$, leucocytosis and abdominal pain.

\section{Statistical analysis}

All data were recorded in a database and processed with statistical software SPSS v15 (SPSS INC, Chicago, USA).

\section{RESULTS}

Between July 2007 and March 2011, 956 ERCP were performed in our Unit. LBS was done in 120 procedures in 109 different patients. This represents $12.5 \%$ of all the procedures.

Cause for ERCP was choledocolitiasis in 90 patients (75\%); cholangitis in $24(20 \%)$ and severe acute pancreatitis in 6 patients $(5 \%)$. In all cases stones that were unremovable by usual techniques were identified in the bile duct.

Out of the 109 patients, 55 were male $(50.4 \%)$ and 54 female $(49.5 \%)$. Mean age was 75.9 years with a range of 25 to 97 years. Thirty-seven patients $(30.8 \%)$ had undergone a previous cholecistectomy.

Main indication for dilation was discrepancy between stone size and distal bile duct diameter in 74 patients $(62 \%)$, other indications were presence of duodenum diverticula in 25 cases $(20,8 \%)$, Billroth II gastrectomy in 1 case $(0,8 \%)$, severe coagulopathy in 8 cases $(6,7 \%)$ and previous sphincterotomy that could not be extended in 12 cases $(10 \%)$.

In case of duodenum diverticula, dilation was used in those cases were the papilla location in the diverticula unabled us to enlarge the sphincteromy enough to extract the stone, but not as a routinely procedure.

Of the 120 cases, $35(29.2 \%)$ had undergone a sphincterotomy during previous ERCP procedure.

Successful removal of all bile duct stone was achieved in 109 of the 120 procedures on a first attempt, of the 11 remaining cases 7 were solved on a second ERCP. This means a $91 \%$ success rate on first attempt and a $96.7 \%$ globally. 
Of the seven cases that underwent a second attempt, two resolved with a Forgarty balloon, four required a second dilation and in one case dilation of the medial portion of the bile duct was performed to extract a remaining stone above a benign stricture.

The four remaining cases were scheduled for surgery without a second ERCP for clinical reasons (bile duct stenosis, open cholecistectomy need for other reasons and gastric neoplasia discovered during the first procedure).

The number of stones removed varied between 1 to 17 , median being 2.8 standard deviation (SD) of 2.3. Size of the stones ranged between 8 to $30 \mathrm{~mm}$ (median 15.2, SD 4.1).

The size of the dilation balloon varied from 10 to $20 \mathrm{~mm}$ (median 13.2, SD 2.3).

Plastic temporary stents were placed in eleven cases. Ten of them were placed as a temporary drainage before a second attempt or prior to surgery and in cases of severe sepsis as precaution measure, in spite of an adequate drainage. Stents were removed in a second procedure taking place between one and seven weeks (median 5 weeks), without further complications.

Mechanical lithotripsy was used only in one case $(0.8 \%)$ in addition to dilation due to the large size of the stones.

Complications: there were no cases of acute pancreatitis. No perforations or cholangitis were noted.

Post-ERCP bleeding was seen in five cases (4.2\%). All of them were graded as moderate, three needed endoscopic sclerosis, while the remaining two were managed conservatively, receiving blood transfusions. Of these five cases, two of them occurred in patients who needed to restart anticoagulant therapy as soon as possible. Both of them had severe cholangitis while ongoing concurrent disease, acute pulmonar thromboembolism in one case and arterial ischemia of a leg in other case. Another case was due to septic coagulopathy in a patient with chronic renal failure in hemodialysis and the other two were patients with antiplatelet therapy that could not be withdrawn. Evolution in all patients was good and all were discharged home without any further complication. Procedure-associated mortality was null.

\section{DISCUSSION}

ERCP in treatment of bile duct stones has achieved a very high success rate, nevertheless around $10 \%$ of the stones are considered "difficult to extract" $(3,4)$. There are alternative procedures such as mechanical lithotripsy, nasobiliar catheters placement, etc., but they can be difficult, time-consuming and have complications.

Sphincteroplasty was initially proposed in the $1990 \mathrm{~s}$ as an alternative to ES, using low-diameter balloons, but safety concerns prevented an extended use, especially since postERPC pancreatitis increased risk reports (14).

Ersoz et al. (5) reported in 2003 the use LBS associated to ES in the management of difficult bile stones, with a suc- cess rate of $83 \%$ in the first procedure, although mechanical lithotripsy was still needed in $7 \%$ of patients. Complication rate in this publication was $16 \%$, including a $3 \%$ of pancreatitis.

Since then, several studies have been published reporting LBS after ES (6-12). A multicentre retrospective study was published in 2008 (10) in 106 patients, with a 95\% success rate, but mechanical lithotripsy was necessary in $27 \%$ of the cases. Complication rate was $6 \%$.

More recently a randomized controlled trial of LBS against mechanical lithotripsy has been published by Stefanidis et al. (12), although prematurely terminated it showed similar efficacy $(97.7 v s .91 .1 \% \mathrm{p}=0.36)$ but with less complications in LBS arm (4.4 vs. 20\%).

In our series, in clinical practice setting, LBS was done when, to the endoscopist criteria, stone removal was not possible or safe with conventional methods, representing cases in a high risk of failure or complication. In this setting our success rate is $91 \%$ in the first procedure and $96.7 \%$ if two attempts were made (Figs. 1 and 2).

This study collects our experience with this technique over four years, including a large number of procedures (120), being one of the largest published series in our setting $(8,11)$. The obtained efficacy is very high, similar to those described previously. Our complication rate supports the safety of this technique. As our experience and confidence in this procedure grew, it was used in a larger number of patients, becoming actually our first option to remove stones where ES and Fogarty balloon have not been successful, displacing lithotripsy, in fact in our series it was only used in one patient $(0.8 \%)$.

Although not measured in this study the reduction in the use of lithotripsy, plastic stents and other methods could lead to shorter procedures and a decrease in the complication rate, for instance, lithotripsy complication rate has been reported to be as high as $20 \%$ including a $13.3 \%$ of cholangitis (12).

Our global ERCP complication rate was $4.2 \%$, due to five patients which presented with moderate hemorrhage. All of these patients had a very high risk for bleeding, because of coagulation alterations, due to anticoagulation or antiplatelet medication that was not possible to withdraw because of comorbidity or due to septic coagulopathy.

It is especially remarkable the null incidence of pancreatitis documented in our series, as high incidence of postERCP pancreatitis has been the main disadvantage to dilation with standard size balloons $(6-10 \mathrm{~mm})$ in the treatment of small size choledocolitiasis (15). This rate could be explained by low frequency of accidental pancreatogram, as this has been reported as an independent risk factor for the development of post-ERCP pancreatitis $(16,17)$. It has also been hypothesized that performing the dilatation after ES could reduce the pressure towards the pancreatic duct (5).

The safety profile of the LBS is strengthened by the fact that this is a clinical practice series, including patients with higher complication risk that would probably have been excluded from randomized clinical trials. 

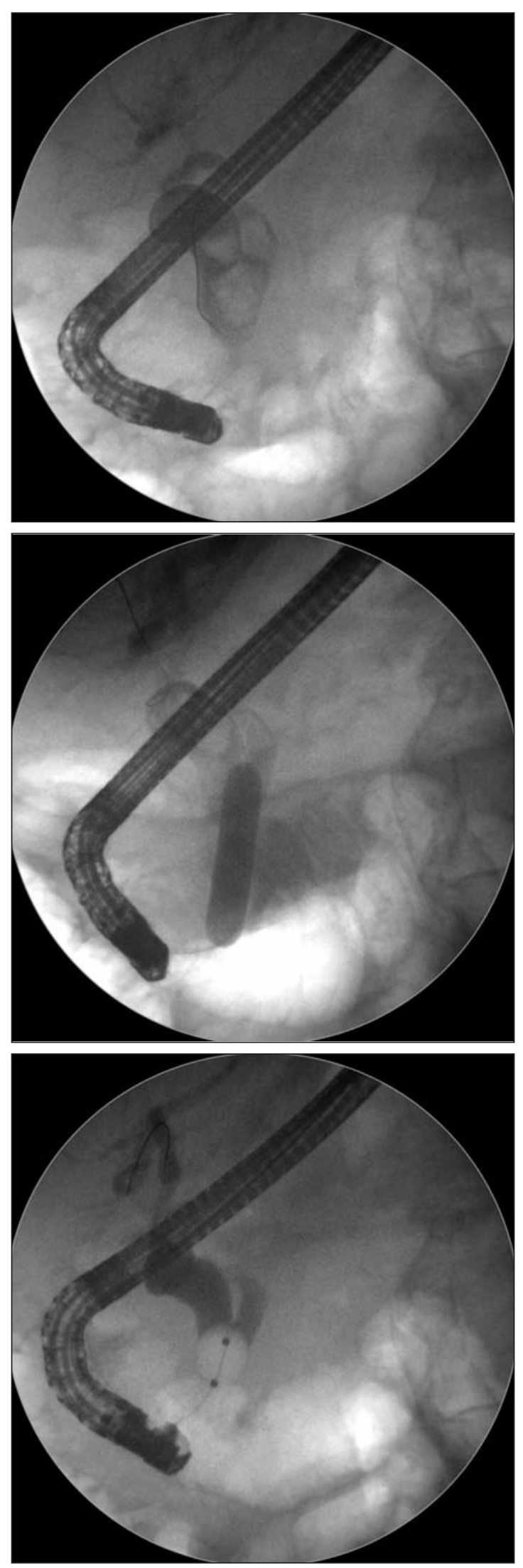

Fig. 1. Radiological series showing stones, inflated balloon, and final outcome.
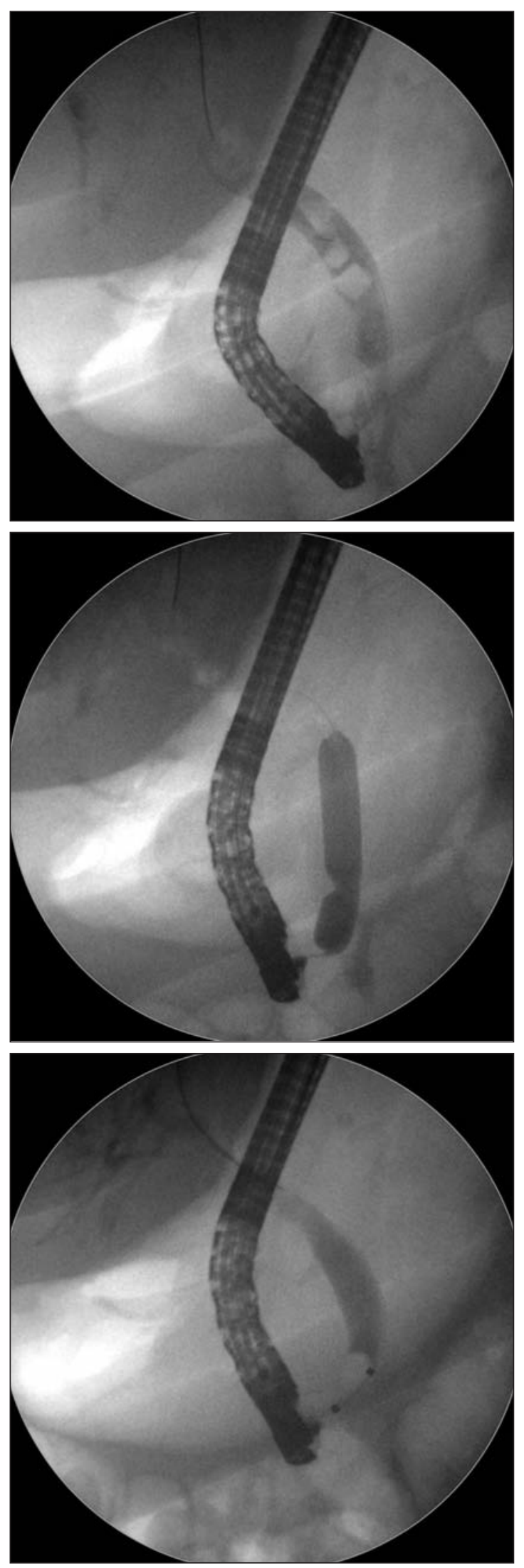

Fig. 2. Radiological series showing choledocolithiasis, inflated balloon with waistline over the papilla, and final outcome. 


\section{CONCLUSION}

LBS after ES is a feasible technique in ERCP. The results obtained with this technique in our centre in a clinical setting show an excellent success rate with a low use of lithotripsy and a very low complication rate.

\section{REFERENCES}

1. Classen M, Demling L. Endoskopische Sphinkterotomie der Papilla Vateri und Steinextraktion aus dem Ductus Choledochus. Dtsch Med Wochenschr 1974;99:496-7.

2. Kawai K, Akasaka Y, Murakami K, Tada M, Koli Y. Endoscopic sphincterotomy of the ampulla of Vater. Gastrointest Endosc 1974; 20:148-51.

3. Binmoeller KF, Bruckner M, Thonke F, Soehendra N. Treatment of difficult bile duct stones using mechanical, electrohydraulic and extracorporeal shock wave lithotripsy. Endoscopy 1993;25:201-6.

4. McHenry L, Lehman G. Difficult bile duct stones. Curr Treat Options Gastroenterol 2006;9:123-32.

5. Ersoz G, Tekesin O, Ozutemiz AO, Gunsar F. Biliary sphincterotomy plus dilation with a large balloon for bile duct stones that are difficult to extract. Gastrointest Endosc 2003;57:156-9.

6. Maydeo A, Bhandari S. Balloon sphincteroplasty for removing difficult bile duct stones. Endoscopy 2007;39:958-61.

7. Minami A, Hirose S, Nomoto T, Hayakawa S. Small sphincterotomy combined with papillary dilation with large balloon permits retrieval of large stones without mechanical lithotripsy. World J Gastroenterol 2007; $13: 2179-82$
8. Espinel J, Pinedo E, Olcoz J. Large hydrostatic balloon for choledocholithiasis. Rev Esp Enferm Dig 2007;99:33-8

9. Heo JH, Kang DH, Jung HJ, Kwon DS, An JK, Kim BS, et al. Endoscopic sphincterotomy plus large balloon dilation versus endoscopic sphincterotomy for removal of bile-duct stones. Gastrointest Endosc 2007;66:720-6

10. Attasaranya S, Cheon YK, Vittal H, Howell DA, Wakelin DE, Cunningham JT, et al. Large-diameter biliary orifice balloon dilation to aid in endoscopic bile duct stone removal: a multicenter series. Gastrointest Endosc 2008;67:1046-52.

11. García-Cano J, Arana LT, Ayllón CJ, Chicano MV, Fernández RM, Sánchez LS, et al. Biliary sphincterotomy dilation for the extraction of difficult common bile duct stones. Rev Esp Enferm Dig 2009; 101:541-5.

12. Stefanidis G, Viazis N, Pleskow D, Manolakopoulos S, Theocharis L Christodoulou C, et al. Large balloon dilation vs. mechanical lithotripsy for the management of large bile duct stones: a prospective randomized study. Am J Gastroenterol 2011;106:278-85.

13. Cotton PB, Lehman G, Vennes J, Geenen JE, Russell RC, Meyers WC, et al. Endoscopic sphincterotomy complications and their management: an attempt at consensus. Gastrointest Endosc 1991;37:383-93.

14. DiSario JA, Freeman ML, Bjorkman DJ, Macmathuna P, Petersen BT Jaffe PE, et al. Endoscopic balloon dilation compared with sphincterotomy for extraction of bile duct stones. Gastroenterology 2004; 127:1291-9.

15. Fujita N, Maguchi H, Komatsu Y, Yasuda I, Hasebe O, Igarashi Y, et al. Endoscopic sphincterotomy and endoscopic papillary balloon dilatation for bile duct stones: A prospective randomized controlled multicenter trial. Gastrointest Endosc 2003;57:151-5.

16. Freeman ML, DiSario JA, Nelson DB, Fennerty MB, Lee JG, Bjorkman DJ, et al. Risk factors for post-ERCP pancreatitis: a prospective, multicenter study. Gastrointest Endosc 2001;54:425-34.

17. Freeman ML, Nelson DB, Sherman S, Haber GB, Herman ME, Dorsher PJ, et al. Complications of endoscopic biliary sphincterotomy. N Engl J Med 1996;335:909-18. 